\title{
Modelamiento numérico de la formación e inestabilidad de bloques alrededor del túnel Monte Seco excavado en un macizo rocoso discontinuo
}

\author{
Numerical modelling of the formation and instability of blocks around the Monte Seco tunnel \\ excavated in a discontinuous rock mass
}

Fecha de entrega: 7 de diciembre 2016 Fecha de aceptación: 10 de abril 2017

\section{Sergio Villalobos ${ }^{1,2}$, Pedro Cacciari ${ }^{1}$ y Marcos Futai ${ }^{1}$}

\begin{abstract}
${ }^{1}$ Departamento de Ingeniería Geotécnica, Escola Politécnica da Universidade de São Paulo, Av. Prof. Luciano Gualberto, travessa 3 N³80, Cidade Universitária, SP, São Paulo, Brasil, svillalobos.ic@gmail.com,ppazzoto@gmail.com, futai@usp.br

${ }^{2}$ OITEC Geotecnia Ltda., Avenida Arturo Prat 199 A - Oficina 702 - Concepción, svillalobos@oitec.cl
\end{abstract}

El análisis geotécnico de túneles en ambientes geoestructurales complejos requiere un entendimiento avanzado del efecto de las estructuras interbloque sobre el comportamiento del macizo rocoso, tales como sistemas de juntas y fracturas, planos de estratificación y foliación, entre otros tipos de discontinuidades. La aproximación convencional para el análisis geotécnico preliminar de túneles se basa en la representación de un sistema continuoequivalente del macizo rocoso, es decir, sin considerar explícitamente los sistemas de discontinuidades sistemáticas. Sin embargo, para obtener resultados más cercanos a la realidad del comportamiento esperado del macizo rocoso, los datos geo-estructurales deben ser incluidos desde la etapa inicial de modelamiento numérico para el análisis geotécnico. El túnel Monte Seco en Brasil, es usado como caso de estudio para analizar las implicaciones de la inclusión de sistemas de discontinuidades, así como la degradación de las propiedades mecánicas en la estabilidad de excavaciones subterráneas. Basándose en la valiosa información de ingeniería geológica del proyecto TUNELCON, se desarrollaron modelos numéricos, en los cuales se generaron sistemas de DFN bidimensionales. El caso estudiado demuestra la importancia de considerar en detalle los datos geo-estructurales en modelos numéricos desde las etapas iniciales de proyecto, logrando con esto resultados que se asemejan de mejor forma al comportamiento real que tienen las excavaciones durante las etapas de construcción y operación.

Palabras clave: túnel en roca, bloque/cuña, sistemas de fracturas, plano de foliación, FEM, DFN
Geotechnical analysis of tunnels in complex geostructural environments requires an advanced understanding of the inter-block structure effect on rock mass behaviour, such as joints and fractures systems, bedding and foliation planes, among other discontinuity types. The conventional approach for preliminary geotechnical analysis of tunnels is based on a continuous-equivalent system representation of rock mass, i.e. without explicit consideration of systematic discontinuity systems. However, to obtain a closer to reality results of the rock mass expected behaviour, geostructural data should be included from the initial stage of numerical modelling for geotechnical analysis. The Monte Seco tunnel in Brazil, is used as a case study to analyze the implications of the discontinuity systems inclusion and degradation of mechanical properties, on the underground excavations stability. Based on the valuable geological engineering information from the TUNELCON project, numerical models with twodimensional DFN systems were developed. The case study demonstrates the importance of considering in detail the geo-structural data in numerical models from early stages of the project, thus achieving results that resemble in a better way to the actual behaviour that have the excavations during the construction and operation stages.

Keywords: tunnel in rock, block/wedge, fracture systems, foliation plane, FEM, DFN

\section{Introducción}

La construcción de mallas de sistemas de discontinuidades geológicamente realistas para el análisis y diseño geotécnico de excavaciones subterráneas está ganando terreno sobre las técnicas convencionales de considerar materiales continuo-equivalentes y sistemas de clasificaciones geomecánicos empíricos. Actualmente, las mallas de fracturas discretas DFNs (Discrete Fracture Networks) es la técnica mayormente usada, la cual ofrece la oportunidad de maximizar el uso de datos geo- 
estructurales recolectados por mapeo geotécnico manual y/o técnicas de muestreo remoto, como fotogrametría digital y escáner láser, i.e., LiDAR o TLS (Elmo et al., 2014). Cacciari y Futai (2015, 2016a, 2016b) han presentado una metodología para simulaciones numéricas tridimensionales de túneles excavados en macizos rocosos discontinuos, basándose en la técnica de escaneo láser terrestre TLS (Terrestrial Laser Scanning) y generación de DFNs. Estos autores han discutido varios aspectos relacionados con el mapeo de discontinuidades mediante TLS, análisis de discontinuidades por métodos de muestreo en ventanas y modelamiento numérico de DFNs.

La construcción de proyectos de excavaciones subterráneas, tales como túneles, cavernas y piques, a menudo son desarrollados en macizos rocosos con sistemas de discontinuidades como fallas, planos de estratificación y foliación, diaclasas y fracturas. Estos sistemas de discontinuidades inducen la formación e inestabilidad de bloques y cuñas de rocas durante las etapas de ejecución y operación de las obras. Los sistemas de discontinuidades usualmente ocurren en forma de conjuntos o sets, los cuales pueden ser descritos geométricamente por su orientación, longitud de traza y espaciamiento. La baja y/o algunas veces nula resistencia al corte de los sistemas de discontinuidades, los altos niveles de esfuerzos in situ, así como las condiciones de pérdida de confinamiento debido a la ejecución de las excavaciones, inducen distintos modos de falla de los bloques/cuñas de roca formados por la intersección de dos o más sistemas de discontinuidades, tales como deslizamiento, volcamiento, y caída dentro de la excavación. Es importante señalar que, bajo algunas condiciones, los sistemas de discontinuidades pueden llevar a grandes desastres para la construcción de proyectos subterráneos.

Para estudiar el efecto de la inclusión de los datos geoestructurales sobre la estabilidad de excavaciones subterráneas desarrolladas en macizos rocosos discontinuos, un tramo del túnel laboratorio Monte Seco perteneciente a la Compañía Minera VALE S.A., localizado en el Estado de Espirito Santo al Sur-Este de Brasil, es simulado mediante modelos numéricos simples considerando un medio elasto-plástico semi-discontinuo. Las simulaciones numéricas fueron realizadas con el software comercial FEM RS2 (2015). Para el material tipo elasto-plástico fue considerado el criterio de resistencia de Hoek-Brown generalizado (Hoek et al., 2002). Este criterio ha sido adaptado de acuerdo con la metodología descrita por Diederichs (2007), donde los parámetros de resistencia máxima y residual son seleccionados de tal forma que ocurra un comportamiento de strain-softening en el perímetro cercano a la excavación, mientras el confinamiento aumenta. La modelación semi-discontinua, que considera explícitamente los sistemas de discontinuidades del macizo rocoso, fue implementada mediante el método de generación de discontinuidades paralelo determinístico (RS2, 2015). Esto se hizo importando directamente los parámetros de entrada, correspondientes en este caso a mediciones con TLS de los sistemas de discontinuidades. De esta forma, se crean planos únicos de discontinuidades definidos por sus características geométricas específicas (orientación principal, longitud de traza y espaciamiento), los cuales generan una malla bi-dimensional de sistemas de discontinuidades.

Son analizados los resultados obtenidos para los modelos elasto-plásticos semi-discontinuos de un tramo del túnel Monte Seco. Los resultados demuestran y destacan el efecto significativo de la modelación explícita de sistemas de discontinuidades de roca sobre los patrones de esfuerzo-deformación alrededor del túnel estudiado, pudiendo visualizar cuantitativamente los efectos sobre la concentración y relajación de esfuerzos, zonas de fluencia, formación de bloques/cuñas y trayectorias de desplazamientos. Además, los resultados son comparados con mediciones de sobre-excavaciones realizadas con TLS, donde se logra obtener una buena similitud con las observaciones de terreno.

\section{Túnel laboratorio Monte Seco}

En Brasil varios túneles antiguos (desde la década de 1950) del sistema de carreteras y ferrocarril fueron construidos en macizos rocosos de muy buena calidad geotécnica sin ningún sistema de refuerzo y soporte. Hoy en día, algunos de estos túneles han presentado problemas localizados de caídas de bloques de roca asociados principalmente con la distribución de sistemas de discontinuidades y procesos de degradación puntual de los parámetros geotécnicos asociados.

El túnel Monte Seco es una antigua obra subterránea lineal 
construida para el ferrocarril Vitória - Minas en el Estado de Espírito Santo al Sur-Este de Brasil (ver Figura 1), perteneciente a la Compañía Minera VALE S.A. Este túnel ha requerido de investigaciones geológicas y geotécnicas para proporcionar parámetros geomecánicos y evaluaciones de estabilidad del mismo (Cacciari y Futai, 2016b).

(a)

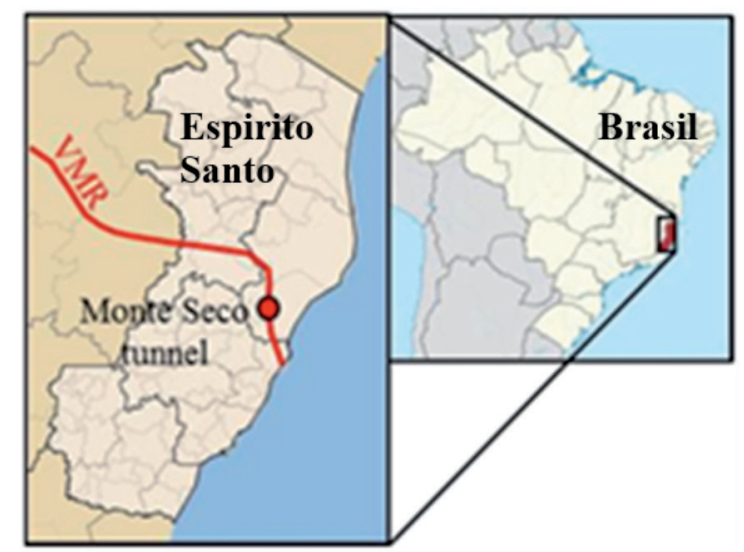

(b)

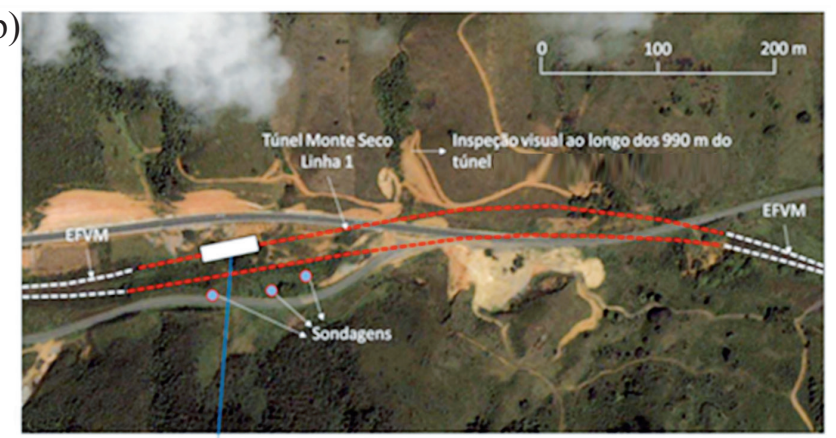

(c)

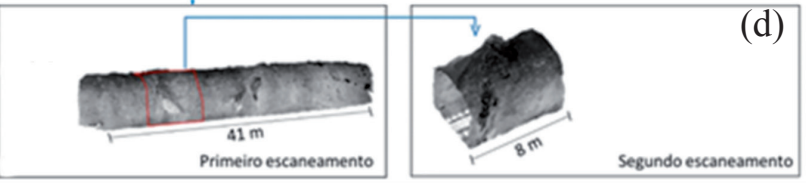

Figura 1: a) Localización túnel Monte Seco, b) fotografía satelital del trazado del túnel Monte Seco (Google Earth), c) nube de puntos del primer TLS, indicando la longitud de $8 \mathrm{~m}$ considerada para el segundo TLS y d) nube de puntos del segundo TLS (Cacciari, 2014).

Considerando el problema anterior, un proyecto de colaboración entre la Escuela Politécnica de la Universidad de São Paulo y VALE S.A., fue iniciado para proponer una metodología de estudio del estado actual de estos túneles (Proyecto TUNELCON). De esta forma, el túnel laboratorio Monte Seco se ha transformado en una fuente de información geomecánica de gran valor para estudiar la estabilidad de obras subterráneas construidas en macizos rocosos discontinuos. A continuación, se presentan las principales características y propiedades consideradas para este trabajo.
Ingeniería geológica
Geoloǵía regional y local
El túnel Monte Seco está localizado en la Provincia de
Mantiqueira, construido en un macizo rocoso conformado
por un Paragneis (metamorfismo de rocas sedimentarias),
con textura milonítica, compuesto por bandas félsicas
(con predominancia de cuarzo y feldespato) y máficas
(con predominancia de biotita y anfibolita), con foliación
pronunciada, principalmente por la orientación de micas.
Además, en varias porciones del interior del túnel,
así como en afloramientos de roca externos, fueron
observados bolsones de Granito insertos en el Paragneis,
con diámetros entre 1 y 3 m, con contacto abrupto, sin
presencia de foliación y con textura pegmatítica. La
Figura 2 muestra el mapa geológico de la Provincia de
Mantiqueira destacando la posición del complejo Araçuai
e Ribeira (región de estudio). Además, son mostradas dos
fotografias correspondientes a las litologías presentes en la
ubicación del túnel estudiado.
(a)

Ingeniería geológica
Geología regional y local
El túnel Monte Seco está localizado en la Provincia de
Mantiqueira, construido en un macizo rocoso conformado
por un Paragneis (metamorfismo de rocas sedimentarias),
con textura milonítica, compuesto por bandas félsicas
(con predominancia de cuarzo y feldespato) y máficas
(con predominancia de biotita y anfibolita), con foliación
pronunciada, principalmente por la orientación de micas.
Además, en varias porciones del interior del túnel,
así como en afloramientos de roca externos, fueron
observados bolsones de Granito insertos en el Paragneis,
con diámetros entre 1 y 3 m, con contacto abrupto, sin
presencia de foliación y con textura pegmatítica. La
Figura 2 muestra el mapa geológico de la Provincia de
Mantiqueira destacando la posición del complejo Araçuai
e Ribeira (región de estudio). Además, son mostradas dos
fotografias correspondientes a las litologías presentes en la
ubicación del túnel estudiado.
(a)

Ingeniería geológíca
Geología regional y local
El túnel Monte Seco está localizado en la Provincia de
Mantiqueira, construido en un macizo rocoso conformado
por un Paragneis (metamorfismo de rocas sedimentarias),
con textura milonítica, compuesto por bandas félsicas
(con predominancia de cuarzo y feldespato) y máficas
(con predominancia de biotita y anfibolita), con foliación
pronunciada, principalmente por la orientación de micas.
Además, en varias porciones del interior del túnel,
así como en afloramientos de roca externos, fueron
observados bolsones de Granito insertos en el Paragneis,
con diámetros entre 1 y 3 m, con contacto abrupto, sin
presencia de foliación y con textura pegmatítica. La
Figura 2 muestra el mapa geológico de la Provincia de
Mantiqueira destacando la posición del complejo Araçuai
e Ribeira (región de estudio). Además, son mostradas dos
fotografías correspondientes a las litologías presentes en la
ubicación del túnel estudiado.
(a) (b)

Ingeniería geológíca
Geología regional y local
El túnel Monte Seco está localizado en la Provincia de
Mantiqueira, construido en un macizo rocoso conformado
por un Paragneis (metamorfismo de rocas sedimentarias),
con textura milonítica, compuesto por bandas félsicas
(con predominancia de cuarzo y feldespato) y máficas
(con predominancia de biotita y anfibolita), con foliación
pronunciada, principalmente por la orientación de micas.
Además, en varias porciones del interior del túnel,
así como en afloramientos de roca externos, fueron
observados bolsones de Granito insertos en el Paragneis,
con diámetros entre 1 y 3 m, con contacto abrupto, sin
presencia de foliación y con textura pegmatítica. La
Figura 2 muestra el mapa geológico de la Provincia de
Mantiqueira destacando la posición del complejo Araçuai
e Ribeira (región de estudio). Además, son mostradas dos
fotografías correspondientes a las litologías presentes en la
ubicación del túnel estudiado.
(a) (b)

Ingeniería geológíca
Geología regional y local
El túnel Monte Seco está localizado en la Provincia de
Mantiqueira, construido en un macizo rocoso conformado
por un Paragneis (metamorfismo de rocas sedimentarias),
con textura milonítica, compuesto por bandas félsicas
(con predominancia de cuarzo y feldespato) y máficas
(con predominancia de biotita y anfibolita), con foliación
pronunciada, principalmente por la orientación de micas.
Además, en varias porciones del interior del túnel,
así como en afloramientos de roca externos, fueron
observados bolsones de Granito insertos en el Paragneis,
con diámetros entre 1 y 3 m, con contacto abrupto, sin
presencia de foliación y con textura pegmatítica. La
Figura 2 muestra el mapa geológico de la Provincia de
Mantiqueira destacando la posición del complejo Araçuai
e Ribeira (región de estudio). Además, son mostradas dos
fotografías correspondientes a las litologías presentes en la
ubicación del túnel estudiado.
(a) (b)

Ingeniería geológíca
Geología regional y local
El túnel Monte Seco está localizado en la Provincia de
Mantiqueira, construido en un macizo rocoso conformado
por un Paragneis (metamorfismo de rocas sedimentarias),
con textura milonítica, compuesto por bandas félsicas
(con predominancia de cuarzo y feldespato) y máficas
(con predominancia de biotita y anfibolita), con foliación
pronunciada, principalmente por la orientación de micas.
Además, en varias porciones del interior del túnel,
así como en afloramientos de roca externos, fueron
observados bolsones de Granito insertos en el Paragneis,
con diámetros entre 1 y 3 m, con contacto abrupto, sin
presencia de foliación y con textura pegmatítica. La
Figura 2 muestra el mapa geológico de la Provincia de
Mantiqueira destacando la posición del complejo Araçuai
e Ribeira (región de estudio). Además, son mostradas dos
fotografías correspondientes a las litologías presentes en la
ubicación del túnel estudiado.
(a) (b)

Ingeniería geológíca
Geología regional y local
El túnel Monte Seco está localizado en la Provincia de
Mantiqueira, construido en un macizo rocoso conformado
por un Paragneis (metamorfismo de rocas sedimentarias),
con textura milonítica, compuesto por bandas félsicas
(con predominancia de cuarzo y feldespato) y máficas
(con predominancia de biotita y anfibolita), con foliación
pronunciada, principalmente por la orientación de micas.
Además, en varias porciones del interior del túnel,
así como en afloramientos de roca externos, fueron
observados bolsones de Granito insertos en el Paragneis,
con diámetros entre 1 y 3 m, con contacto abrupto, sin
presencia de foliación y con textura pegmatítica. La
Figura 2 muestra el mapa geológico de la Provincia de
Mantiqueira destacando la posición del complejo Araçuai
e Ribeira (región de estudio). Además, son mostradas dos
fotografías correspondientes a las litologías presentes en la
ubicación del túnel estudiado.
(a) (b)

Ingeniería geológíca
Geología regional y local
El túnel Monte Seco está localizado en la Provincia de
Mantiqueira, construido en un macizo rocoso conformado
por un Paragneis (metamorfismo de rocas sedimentarias),
con textura milonítica, compuesto por bandas félsicas
(con predominancia de cuarzo y feldespato) y máficas
(con predominancia de biotita y anfibolita), con foliación
pronunciada, principalmente por la orientación de micas.
Además, en varias porciones del interior del túnel,
así como en afloramientos de roca externos, fueron
observados bolsones de Granito insertos en el Paragneis,
con diámetros entre 1 y 3 m, con contacto abrupto, sin
presencia de foliación y con textura pegmatítica. La
Figura 2 muestra el mapa geológico de la Provincia de
Mantiqueira destacando la posición del complejo Araçuai
e Ribeira (región de estudio). Además, son mostradas dos
fotografías correspondientes a las litologías presentes en la
ubicación del túnel estudiado.
(a) (b)

Ingeniería geológíca
Geología regional y local
El túnel Monte Seco está localizado en la Provincia de
Mantiqueira, construido en un macizo rocoso conformado
por un Paragneis (metamorfismo de rocas sedimentarias),
con textura milonítica, compuesto por bandas félsicas
(con predominancia de cuarzo y feldespato) y máficas
(con predominancia de biotita y anfibolita), con foliación
pronunciada, principalmente por la orientación de micas.
Además, en varias porciones del interior del túnel,
así como en afloramientos de roca externos, fueron
observados bolsones de Granito insertos en el Paragneis,
con diámetros entre 1 y 3 m, con contacto abrupto, sin
presencia de foliación y con textura pegmatítica. La
Figura 2 muestra el mapa geológico de la Provincia de
Mantiqueira destacando la posición del complejo Araçuai
e Ribeira (región de estudio). Además, son mostradas dos
fotografías correspondientes a las litologías presentes en la
ubicación del túnel estudiado.
(a) (b)

Ingeniería geológíca
Geología regional y local
El túnel Monte Seco está localizado en la Provincia de
Mantiqueira, construido en un macizo rocoso conformado
por un Paragneis (metamorfismo de rocas sedimentarias),
con textura milonítica, compuesto por bandas félsicas
(con predominancia de cuarzo y feldespato) y máficas
(con predominancia de biotita y anfibolita), con foliación
pronunciada, principalmente por la orientación de micas.
Además, en varias porciones del interior del túnel,
así como en afloramientos de roca externos, fueron
observados bolsones de Granito insertos en el Paragneis,
con diámetros entre 1 y 3 m, con contacto abrupto, sin
presencia de foliación y con textura pegmatítica. La
Figura 2 muestra el mapa geológico de la Provincia de
Mantiqueira destacando la posición del complejo Araçuai
e Ribeira (región de estudio). Además, son mostradas dos
fotografías correspondientes a las litologías presentes en la
ubicación del túnel estudiado.
(a) (b)

Ingeniería geológíca
Geología regional y local
El túnel Monte Seco está localizado en la Provincia de
Mantiqueira, construido en un macizo rocoso conformado
por un Paragneis (metamorfismo de rocas sedimentarias),
con textura milonítica, compuesto por bandas félsicas
(con predominancia de cuarzo y feldespato) y máficas
(con predominancia de biotita y anfibolita), con foliación
pronunciada, principalmente por la orientación de micas.
Además, en varias porciones del interior del túnel,
así como en afloramientos de roca externos, fueron
observados bolsones de Granito insertos en el Paragneis,
con diámetros entre 1 y 3 m, con contacto abrupto, sin
presencia de foliación y con textura pegmatítica. La
Figura 2 muestra el mapa geológico de la Provincia de
Mantiqueira destacando la posición del complejo Araçuai
e Ribeira (región de estudio). Además, son mostradas dos
fotografías correspondientes a las litologías presentes en la
ubicación del túnel estudiado.
(a) (b)

Ingeniería geológíca
Geología regional y local
El túnel Monte Seco está localizado en la Provincia de
Mantiqueira, construido en un macizo rocoso conformado
por un Paragneis (metamorfismo de rocas sedimentarias),
con textura milonítica, compuesto por bandas félsicas
(con predominancia de cuarzo y feldespato) y máficas
(con predominancia de biotita y anfibolita), con foliación
pronunciada, principalmente por la orientación de micas.
Además, en varias porciones del interior del túnel,
así como en afloramientos de roca externos, fueron
observados bolsones de Granito insertos en el Paragneis,
con diámetros entre 1 y 3 m, con contacto abrupto, sin
presencia de foliación y con textura pegmatítica. La
Figura 2 muestra el mapa geológico de la Provincia de
Mantiqueira destacando la posición del complejo Araçuai
e Ribeira (región de estudio). Además, son mostradas dos
fotografías correspondientes a las litologías presentes en la
ubicación del túnel estudiado.
(a) (b)

Ingeniería geológíca
Geología regional y local
El túnel Monte Seco está localizado en la Provincia de
Mantiqueira, construido en un macizo rocoso conformado
por un Paragneis (metamorfismo de rocas sedimentarias),
con textura milonítica, compuesto por bandas félsicas
(con predominancia de cuarzo y feldespato) y máficas
(con predominancia de biotita y anfibolita), con foliación
pronunciada, principalmente por la orientación de micas.
Además, en varias porciones del interior del túnel,
así como en afloramientos de roca externos, fueron
observados bolsones de Granito insertos en el Paragneis,
con diámetros entre 1 y 3 m, con contacto abrupto, sin
presencia de foliación y con textura pegmatítica. La
Figura 2 muestra el mapa geológico de la Provincia de
Mantiqueira destacando la posición del complejo Araçuai
e Ribeira (región de estudio). Además, son mostradas dos
fotografías correspondientes a las litologías presentes en la
ubicación del túnel estudiado.
(a) (b)

Ingeniería geológíca
Geología regional y local
El túnel Monte Seco está localizado en la Provincia de
Mantiqueira, construido en un macizo rocoso conformado
por un Paragneis (metamorfismo de rocas sedimentarias),
con textura milonítica, compuesto por bandas félsicas
(con predominancia de cuarzo y feldespato) y máficas
(con predominancia de biotita y anfibolita), con foliación
pronunciada, principalmente por la orientación de micas.
Además, en varias porciones del interior del túnel,
así como en afloramientos de roca externos, fueron
observados bolsones de Granito insertos en el Paragneis,
con diámetros entre 1 y 3 m, con contacto abrupto, sin
presencia de foliación y con textura pegmatítica. La
Figura 2 muestra el mapa geológico de la Provincia de
Mantiqueira destacando la posición del complejo Araçuai
e Ribeira (región de estudio). Además, son mostradas dos
fotografías correspondientes a las litologías presentes en la
ubicación del túnel estudiado.
(a) (b)

Ingeniería geológíca
Geología regional y local
El túnel Monte Seco está localizado en la Provincia de
Mantiqueira, construido en un macizo rocoso conformado
por un Paragneis (metamorfismo de rocas sedimentarias),
con textura milonítica, compuesto por bandas félsicas
(con predominancia de cuarzo y feldespato) y máficas
(con predominancia de biotita y anfibolita), con foliación
pronunciada, principalmente por la orientación de micas.
Además, en varias porciones del interior del túnel,
así como en afloramientos de roca externos, fueron
observados bolsones de Granito insertos en el Paragneis,
con diámetros entre 1 y 3 m, con contacto abrupto, sin
presencia de foliación y con textura pegmatítica. La
Figura 2 muestra el mapa geológico de la Provincia de
Mantiqueira destacando la posición del complejo Araçuai
e Ribeira (región de estudio). Además, son mostradas dos
fotografías correspondientes a las litologías presentes en la
ubicación del túnel estudiado.
(a) (b)

Ingeniería geológíca
Geología regional y local
El túnel Monte Seco está localizado en la Provincia de
Mantiqueira, construido en un macizo rocoso conformado
por un Paragneis (metamorfismo de rocas sedimentarias),
con textura milonítica, compuesto por bandas félsicas
(con predominancia de cuarzo y feldespato) y máficas
(con predominancia de biotita y anfibolita), con foliación
pronunciada, principalmente por la orientación de micas.
Además, en varias porciones del interior del túnel,
así como en afloramientos de roca externos, fueron
observados bolsones de Granito insertos en el Paragneis,
con diámetros entre 1 y 3 m, con contacto abrupto, sin
presencia de foliación y con textura pegmatítica. La
Figura 2 muestra el mapa geológico de la Provincia de
Mantiqueira destacando la posición del complejo Araçuai
e Ribeira (región de estudio). Además, son mostradas dos
fotografías correspondientes a las litologías presentes en la
ubicación del túnel estudiado.
(a) (b)

Ingeniería geológíca
Geología regional y local
El túnel Monte Seco está localizado en la Provincia de
Mantiqueira, construido en un macizo rocoso conformado
por un Paragneis (metamorfismo de rocas sedimentarias),
con textura milonítica, compuesto por bandas félsicas
(con predominancia de cuarzo y feldespato) y máficas
(con predominancia de biotita y anfibolita), con foliación
pronunciada, principalmente por la orientación de micas.
Además, en varias porciones del interior del túnel,
así como en afloramientos de roca externos, fueron
observados bolsones de Granito insertos en el Paragneis,
con diámetros entre 1 y 3 m, con contacto abrupto, sin
presencia de foliación y con textura pegmatítica. La
Figura 2 muestra el mapa geológico de la Provincia de
Mantiqueira destacando la posición del complejo Araçuai
e Ribeira (región de estudio). Además, son mostradas dos
fotografías correspondientes a las litologías presentes en la
ubicación del túnel estudiado.
(a) (b)

Ingeniería geológíca
Geología regional y local
El túnel Monte Seco está localizado en la Provincia de
Mantiqueira, construido en un macizo rocoso conformado
por un Paragneis (metamorfismo de rocas sedimentarias),
con textura milonítica, compuesto por bandas félsicas
(con predominancia de cuarzo y feldespato) y máficas
(con predominancia de biotita y anfibolita), con foliación
pronunciada, principalmente por la orientación de micas.
Además, en varias porciones del interior del túnel,
así como en afloramientos de roca externos, fueron
observados bolsones de Granito insertos en el Paragneis,
con diámetros entre 1 y 3 m, con contacto abrupto, sin
presencia de foliación y con textura pegmatítica. La
Figura 2 muestra el mapa geológico de la Provincia de
Mantiqueira destacando la posición del complejo Araçuai
e Ribeira (región de estudio). Además, son mostradas dos
fotografías correspondientes a las litologías presentes en la
ubicación del túnel estudiado.
(a) (b)

Ingeniería geológíca
Geología regional y local
El túnel Monte Seco está localizado en la Provincia de
Mantiqueira, construido en un macizo rocoso conformado
por un Paragneis (metamorfismo de rocas sedimentarias),
con textura milonítica, compuesto por bandas félsicas
(con predominancia de cuarzo y feldespato) y máficas
(con predominancia de biotita y anfibolita), con foliación
pronunciada, principalmente por la orientación de micas.
Además, en varias porciones del interior del túnel,
así como en afloramientos de roca externos, fueron
observados bolsones de Granito insertos en el Paragneis,
con diámetros entre 1 y 3 m, con contacto abrupto, sin
presencia de foliación y con textura pegmatítica. La
Figura 2 muestra el mapa geológico de la Provincia de
Mantiqueira destacando la posición del complejo Araçuai
e Ribeira (región de estudio). Además, son mostradas dos
fotografías correspondientes a las litologías presentes en la
ubicación del túnel estudiado.
(a) (b)

Ingeniería geológíca
Geología regional y local
El túnel Monte Seco está localizado en la Provincia de
Mantiqueira, construido en un macizo rocoso conformado
por un Paragneis (metamorfismo de rocas sedimentarias),
con textura milonítica, compuesto por bandas félsicas
(con predominancia de cuarzo y feldespato) y máficas
(con predominancia de biotita y anfibolita), con foliación
pronunciada, principalmente por la orientación de micas.
Además, en varias porciones del interior del túnel,
así como en afloramientos de roca externos, fueron
observados bolsones de Granito insertos en el Paragneis,
con diámetros entre 1 y 3 m, con contacto abrupto, sin
presencia de foliación y con textura pegmatítica. La
Figura 2 muestra el mapa geológico de la Provincia de
Mantiqueira destacando la posición del complejo Araçuai
e Ribeira (región de estudio). Además, son mostradas dos
fotografías correspondientes a las litologías presentes en la
ubicación del túnel estudiado.
(a) (b)

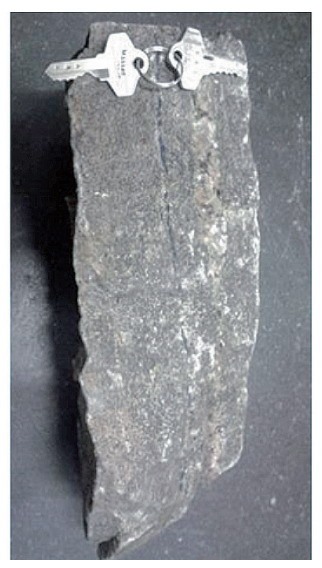

Figura 2: a) Paragneis, b) Granito c) Mapa geológico de la Provincia de Mantiqueira destacando la posición del complejo Araçuai e Ribeira (Cacciari, 2014; Hasui et al., 2012; Monticelli et al., 2014) 


\section{Mapeo y caracterización de los sistemas de discontinuidades}

Cacciari y Futai $(2015,2016 a, b)$ han caracterizado geotécnicamente los sistemas de discontinuidades usando la técnica remota de escáner láser tridimensional TLS para generar las nubes de puntos mostradas en la Figura $3 \mathrm{a}$. Ellos también han utilizado el software PolyWorks para realizar el mapeo de discontinuidades. La metodología empleada puede ser resumida en los siguientes pasos:

I - Mapeo completo de discontinuidades en las nubes de puntos TLS midiendo todas las posiciones, longitudes de traza y orientaciones de cada conjunto de discontinuidades.

II - Análisis de discontinuidades para determinar las funciones de densidad de probabilidad PDF de los diámetros y orientaciones de cada conjunto de discontinuidades.

III - Cálculo del parámetro de intensidad volumétrica $P_{32}$ de cada conjunto de discontinuidades. Este último parámetro es utilizado para generar mallas de DFN-DEM tridimensionales. En el presente trabajo no es estudiado el efecto de este parámetro.

El mapeo de los sistemas de discontinuidades en la nube de puntos TLS consiste básicamente en la interpretación de las discontinuidades presentes en la superficie de roca del túnel tales como losa, paredes y techo, y hacer sus respectivas mediciones. La orientación es medida mediante la selección de puntos co-planares a lasáreas expuestas de las discontinuidades y extrayendo el vector normal al planos ajustado para estos puntos. A continuación, los vectores normales medidos son convertidos a la notación geo-estructural. Las trazas son la intersección entre las discontinuidades y la superficie de roca expuesta dentro del túnel. Las longitudes de traza son medidas tomando la distancia entre los puntos finales de las polilíneas ajustadas en estas trazas. Las Figuras 3b,c muestran ejemplos de las mediciones de longitudes de traza y orientación de discontinuidades en la nube de puntos.

\section{Datos geo-estructurales}

El túnel laboratorio Monte Seco fue construido en un macizo rocoso de Gneis, donde fueron identificados y caracterizados cuatro sistemas de discontinuidades durante la inspección in situ. Dos sistemas de fracturas por corte F1 y F2, un sistema de diaclasamiento laminar F3, y un sistema de foliación Sn. Estos sistemas de discontinuidades fueron mapeados en detalle con las imágenes TLS. La Figura 4a
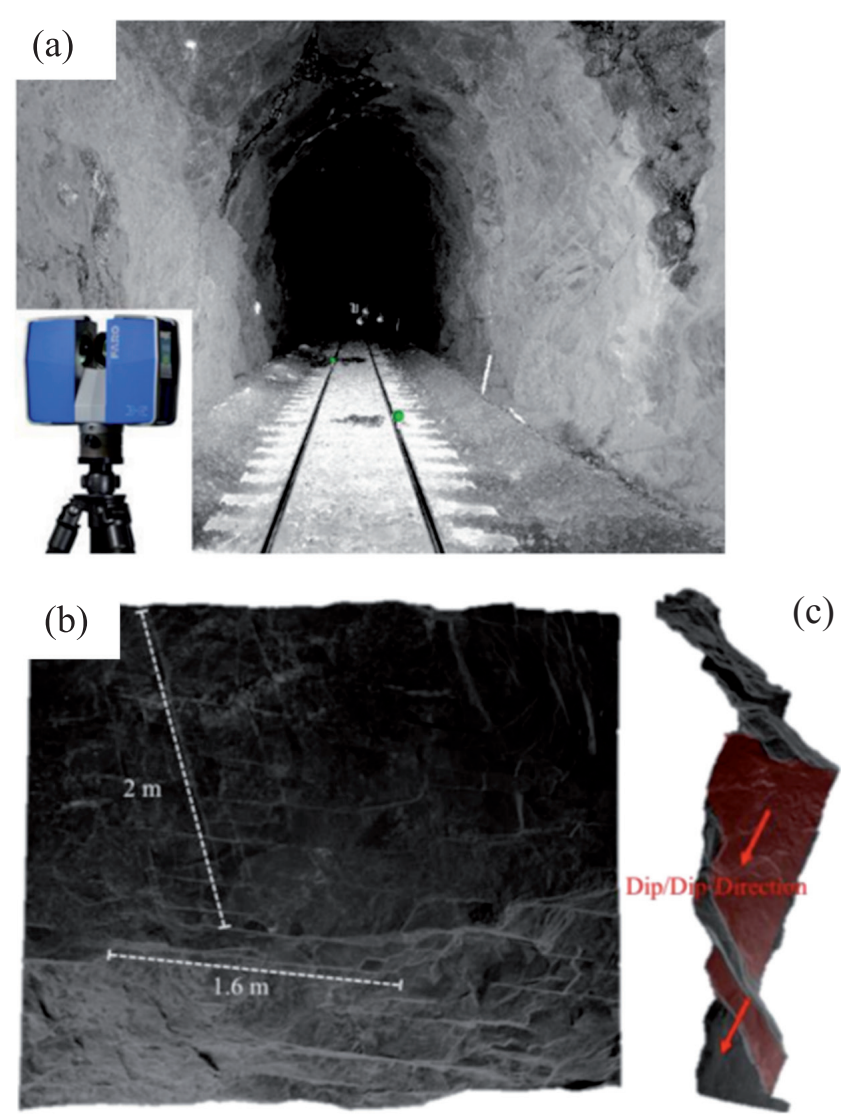

Figura 3: a) Láser escáner modelo Faro Focus 3D y un ejemplo de la imagen TLS del túnel Monte Seco (nube de puntos) generada por este instrumento, b) medición de longitudes de traza y c) medición de orientación (Cacciari y Futai, 2016b)

muestra las mediciones de orientación en las imágenes TLS con la identificación de cada uno de estos sistemas y el eje del túnel.

En la mayoría de los casos encontrados en la literatura técnica, las longitudes de traza son descritas mediante distribuciones log-normal, gamma o exponencial (McMahon, 1974; Call et al., 1976; Baecher et al., 1977; Priest y Hudson, 1981; Kulatilake y Wu, 1984; Villaescusa y Brown, 1992; Zhang y Einstein, 2000). Todas las longitudes de traza de los sistemas F1, F2 y F3 mapeados en las imágenes TLS del túnel fueron analizados por tests estadísticos para encontrar la forma de la distribución que mejor se ajusta (Cacciari y Futai, 2016b). La Figura 4b muestra la distribución mejor ajustada para cada sistema de discontinuidad (log-normal en todos los casos). E1 sistema de foliación es considerado persistente en la escala del túnel, por lo tanto, sus trazas no fueron analizadas de forma estadística.

Para el presente trabajo se considera una sección de túnel de $8 \mathrm{~m}$ de longitud, donde particularmente el sistema F3 no 
fue encontrado (Cacciari y Futai, 2016a,b). Los datos geoestructurales considerados para el presente análisis están sumariados en la Tabla 1.

(a)
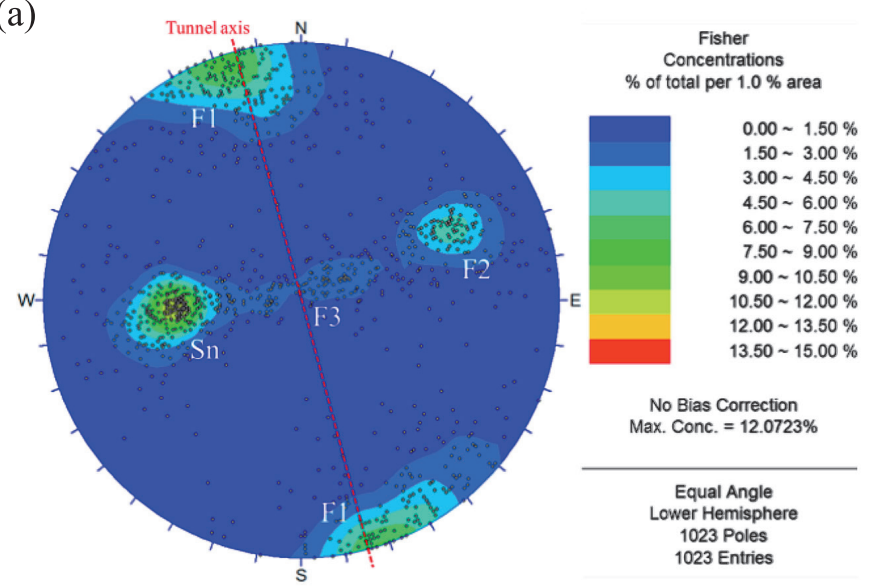

(b)
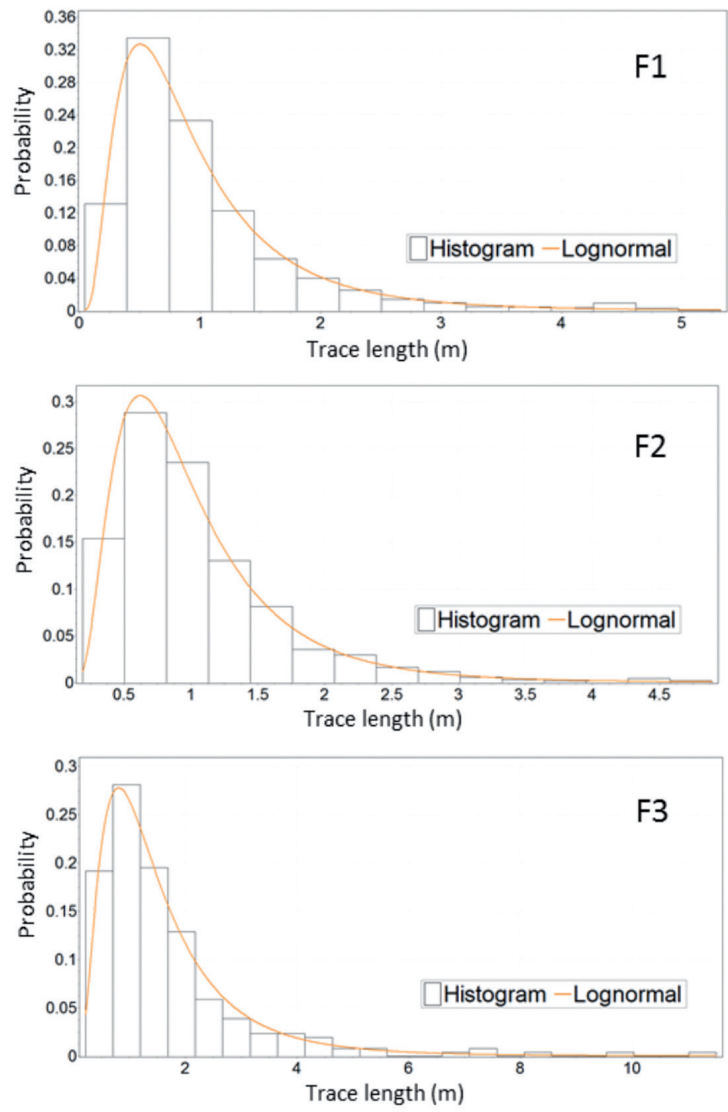

Figura 4: a) Red estereográfica de los datos geo-estructurales (polos) medidos con imágenes TLS y b) ajuste de distribuciones log-normal para los datos de longitud de traza de los sistemas F1, F2 y F3 (Cacciari y Futai, 2016 b)

\section{Ensayos de laboratorio}

Siguiendo las recomendaciones indicadas por la Sociedad Internacional de Mecánica de Rocas ISRM (Bieniawski y Bernede, 1979; Ulusay, 2015), ensayos de compresión simple
Tabla 1: Datos geo-estructurales utilizados para la generación de DFN bi-dimensional (Cacciari y Futai, 2015, 2016a)

\begin{tabular}{|l|c|c|c|}
\hline Sistema & F1 & F2 & Sn \\
\hline Dip, $^{\circ}$ & 69 & 64 & 54 \\
\hline Dip direction, $^{\circ}$ & 166 & 242 & 80 \\
\hline K (Fisher) & 32.8 & 251.3 & 78.9 \\
\hline St. Dev. $^{\text {o }}$ & 15.2 & 5.5 & 9.8 \\
\hline Espaciamiento, $\mathrm{m}^{\circ}$ & 0.48 & 0.32 & 0.5 \\
\hline Long. de traza, $\mathrm{m}$ & 3.67 & 3.91 & Infinita \\
\hline
\end{tabular}

UCS fueron realizados considerando tres orientaciones del sistema de foliación según se muestra en las Figuras 5a,b y c. Además, se efectúo la medición de deformaciones axial y radial utilizando straing gauges instalados en los cuerpos de prueba. Con lo anterior se logró obtener la resistencia a la compresión no confinada $\sigma_{c i}$ y los parámetros elásticos, módulo de elasticidad $E_{i}$ y coeficiente de Poisson $v$ de la roca intacta (Ito, 2016). Estos parámetros son utilizados posteriormente en la modelación numérica.

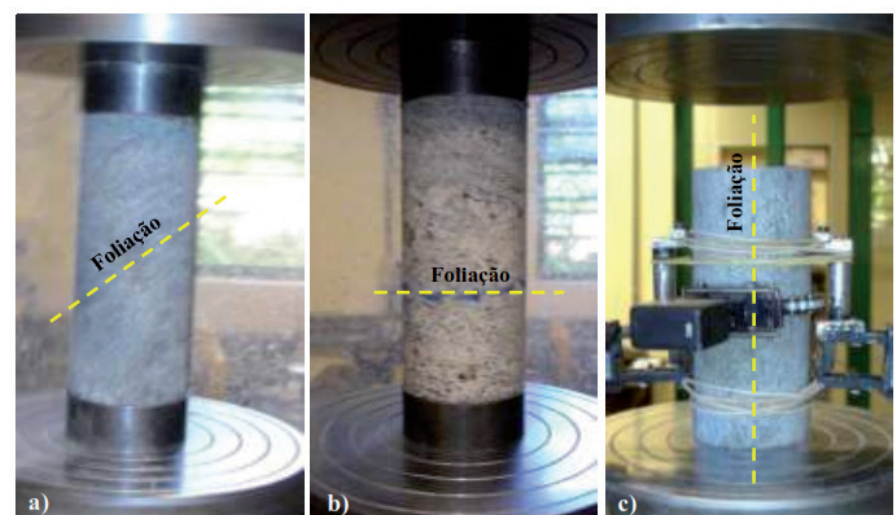

Figura 5: Probetas de roca de ensayos UCS: a) con plano de foliación inclinado a $35^{\circ}$, b) con plano de foliación horizontal y c) con plano de foliación vertical (Ito, 2016)

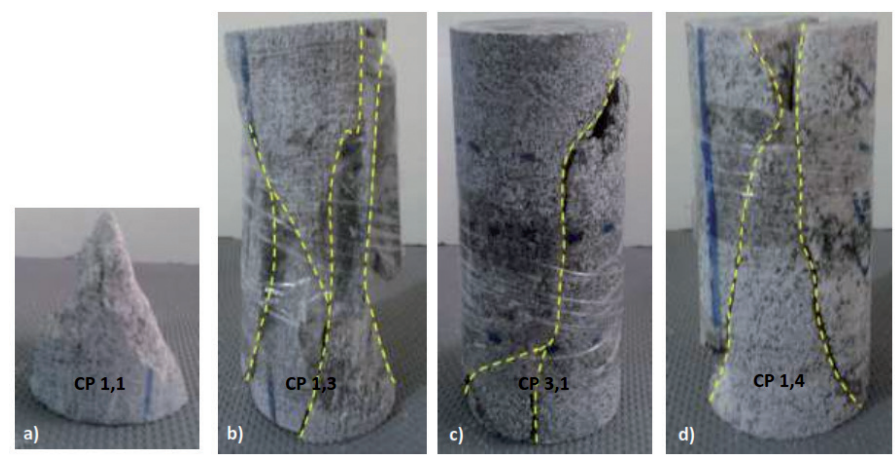

Figura 6: Modos de falla: a) falla violenta sin recuperación, b) falla en varios planos con recuperación, c) falla a lo largo de un plano con recuperación y d) falla a lo largo de dos planos con recuperación (Ito, 2016) 
Las Figuras 6a,b,c y d muestran los principales tipos de falla observados en los ensayos de compresión no confinada. Los modos de falla tipo a) y b) fueron característicos para los cuerpos de prueba más íntegros por inspección visual (sin alteración visible). Los modos de falla c) y d) fueron característicos para los cuerpos de prueba que presentaban cierto grado de alteración en la roca, decoloración y/o disminución de brillo vítreo (Ito, 2016).

La Tabla 2 presenta un resumen de los resultados obtenidos para los ensayos de compresión no confinada. Notar que no se aprecia una influencia significativa de la orientación del sistema de foliación del Gneis sobre la resistencia a la compresión no confinada. Sin embargo, una fuerte reducción fue apreciada en la resistencia (cercana al 50\%) de cuerpos de prueba con presencia de minerales alterados o grietas.

Tabla 2: Resultados ensayos de compresión no confinada (Ito, 2016)

\begin{tabular}{|l|l|r|r|r|}
\hline $\begin{array}{l}\text { Ensayo } \\
\alpha^{o}\end{array}$ & $\mathrm{CP}$ & $\begin{array}{l}\sigma_{\text {ci(medio })} \\
\mathrm{MPa}\end{array}$ & $\begin{array}{l}E_{\mathrm{i}(\mathrm{medio})} \\
\mathrm{GPa}\end{array}$ & $v_{\text {medio }}(-)$ \\
\hline 0 & Gneis & 121 & 51 & 0.394 \\
\hline 35 & Gneis & 159 & 80 & 0.241 \\
\hline 90 & Gneis & 139 & 67 & 0.181 \\
\hline
\end{tabular}

Además, para determinar los parámetros geotécnicos de los sistemas de discontinuidades $\left(J C S, J R C, \phi_{\mathrm{r}}, K_{N} \mathrm{y} K_{S}\right.$ ) se han realizado una serie de distintos ensayos sobre cuerpos de prueba: tracción directa e indirecta, tilt test y esclerómetro (Barrios, 2014; Ito, 2016; Monticelli, 2014). Actualmente, se continúa haciendo ensayos de tracción directa sobre los planos de foliación y ensayos de corte directo con rigidez normal constante sobre planos de fractura. Los resultados de estos ensayos están siendo analizados para la calibración de futuros modelos numéricos de estudio.

Para los tres sistemas de discontinuidades (F1, F2 y Sn), fue considerado el criterio de falla de Barton-Bandis (Bandis et al., 1981; Barton et al., 1985). La Tabla 3 presenta un resumen de los parámetros geotécnicos correspondientes a cada sistema de discontinuidades.

\section{Degradación de los planos de discontinui- dad}

Un aspecto muy importante e influyente dentro de esta investigación es la degradación que han experimentado los
Tabla 3: Parámetros geotécnicos de los sistemas de discontinuidades (Barrios, 2014; Cacciari, 2014; Ito, 2016; Monticelli, 2014)

\begin{tabular}{|l|c|c|c|c|c|c|}
\hline \multirow{2}{*}{$\begin{array}{l}\text { Parámetro } \\
\text { (situación) }\end{array}$} & \multicolumn{3}{|c|}{ F1 y F2 } & \multicolumn{3}{c|}{ Sn } \\
\cline { 2 - 7 } & Inicial & Media & Final & Inicial & Media & Final \\
\hline$J C S, \mathrm{MPa}$ & 80 & 120 & 140 & 120 & 120 & 140 \\
\hline$J R C$ & 9 & 10 & 13 & 8 & 8 & 10.5 \\
\hline$\phi_{r^{\circ}}{ }^{\circ}$ & 23 & 25 & 29 & 24 & 30 & 30 \\
\hline$K_{N^{\prime}} \mathrm{MPa} / \mathrm{m}$ & \multicolumn{3}{|c|}{3500} & \multicolumn{3}{c|}{2800} \\
\hline$K_{S}, \mathrm{MPa} / \mathrm{m}$ & \multicolumn{3}{|c|}{350} & \multicolumn{3}{c|}{280} \\
\hline
\end{tabular}

distintos planos de discontinuidad con el pasar del tiempo. Monticelli (2014) realizó la caracterización de los procesos de alteración del macizo rocoso del túnel Monte Seco, concluyendo que el tipo de intemperismo es de tipo químico de intensidad moderada a fuerte, presentando un fuerte control estructural relacionado a la presencia de sistemas de fracturas y foliación. La foliación intensifica el proceso de alteración de la matriz rocosa de los bloques formados alrededor del túnel, facilitando la percolación de agua a través de las fisuras inter y trans minerales formadas en los planos alterados (ver Figura 7). Tanto en la matriz rocosa, como en los planos de discontinuidad los distintos grados de alteración presentan característica micro morfológicas (fisuras y poros) relacionadas a un proceso de expansióncontracción de la mineralogía secundaria conformada por agregados de Pirita, Clorita y Esmectita, siendo esta última confirmada en los ensayos de difractometría de rayos X. La Figura 7 muestra la fotomicrografía de una fractura con alteración tipo A2 (medianamente alterado). En estas imágenes se puede observar el proceso de alteración controlado por las fisuras inter minerales conectadas a lo largo de la foliación. Notar que las fisuras trans minerales son bastante expresivas y paralelas al plano de fractura, y ocurren sin y con relleno de Óxidos de Fierro Clorita.

Las correlaciones entre los ensayos de porosidad aparente, esclerómetro y resistencia a la compresión no confinada permitieron realizar una estimativa de la degradación de los parámetros de resistencia a la compresión de las discontinuidades JCS y el ángulo de fricción residual $\phi_{r}$ considerados en la metodología de Barton y Choubey (1977). Esto es representado de una forma simple en los datos indicados en la Tabla 3. 

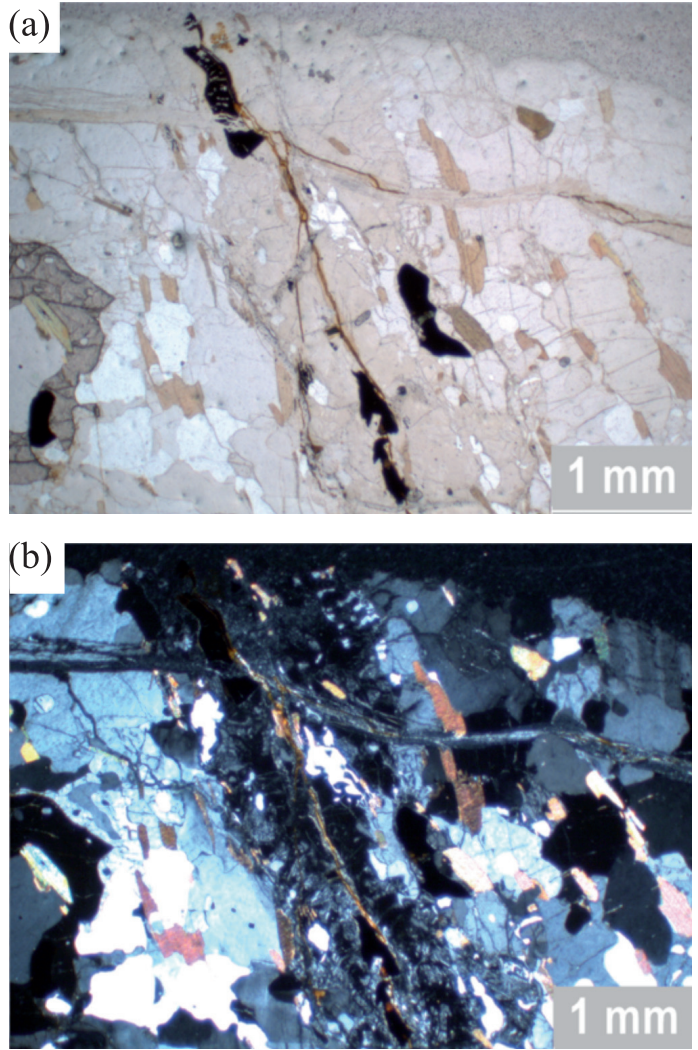

Figura 7: Fotomicrografía de un sistema de fractura con alteración tipo A2: Plano de foliación Gnéisica (sub-vertical) interceptado por un plano de fractura horizontal, a) filtro de luz paralelo a la superficie de roca y b) filtro de luz perpendicular o cruzado a la superficie de roca

\section{Detalles de la simulación numérica}

Basándose en la información geológica y geotécnica descrita anteriormente, fueron desarrollados modelos numéricos elasto-plásticos semi-discontinuos en un software comercial de elementos finitos. A continuación, se describe la metodología.

\section{Geometría y condiciones de borde}

La simulación numérica de túneles excavados en macizos rocosos es una herramienta bastante útil que permite estimar diversos parámetros como trayectoria de esfuerzos y deformaciones, zonas de fluencia, etc., bajo distintas condiciones geométricas y de contorno impuestas. En este trabajo es utilizado el software FEM RS2 (2015) para modelar la influencia de los sistemas de discontinuidades sobre la formación e inestabilidad de bloques en el contorno del túnel Monte Seco.

La geometría del túnel está definida con forma de herradura con diámetro medio igual a $6.25 \mathrm{~m}$ como se muestra en la
Figura 8. El estado de esfuerzo vertical in situ fue estimado considerando la columna litológica sobre el techo del túnel, y con una razón de esfuerzos $K_{0}=1.5$. Debido a que el principal objetivo de este trabajo es observar el comportamiento del macizo rocoso alrededor del túnel, los bordes del modelo han sido restringidos en dirección horizontal y vertical. El tipo de malla de elementos finitos usada fue triangular con 6 nodos, considerando una mayor densidad de elementos cerca de la excavación.

(a)

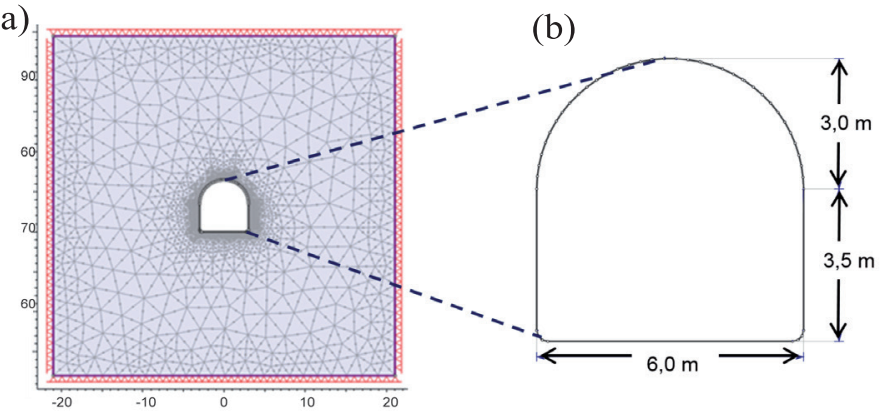

Figura 8: a) Mallado, geometría y condiciones de borde y b) sección regular tipo herradura

\section{Material elasto-plástico}

Para el modelo con material continuo-equivalente fue considerado el criterio de resistencia de Hoek y Brown generalizado (Hoek et al., 2002). Este modelo ha sido adaptado de acuerdo con la metodología descrita por Diederichs (2007), donde los parámetros de resistencia máxima y residual son seleccionados tal que ocurra un comportamiento de strain-softening en el perímetro cercano a la excavación, mientras el confinamiento aumenta.

\section{Generación de DFN bi-dimensionales}

El análisis numérico semi-discontinuo fue realizado considerando explícitamente los datos geo-estructurales para estudiar la formación e inestabilidad de bloques de roca alrededor del túnel. Como se indicó anteriormente, el macizo rocoso fue modelado como un material de tipo elasto-plástico interceptado por sistemas de discontinuidades geológicas, utilizando los parámetros indicados en la Tabla 1. De esta forma, se puede prever el tipo de fallas principales controladas por los sistemas de discontinuidades. El modelo numérico semi-discontinuo proporciona una herramienta de análisis que permite que los bloques formados se deslicen a lo largo de los sistemas de discontinuidad. 
El método utilizado para la generación de DFN bidimensionales permite definir una malla de sistemas de discontinuidades paralelos con ajuste de espaciamiento y orientación (Figura 9). De esta forma, la orientación, el espaciamiento y la longitud de traza de los sistemas de fracturas y planos de foliación son asumidos constantes, es decir, sin variación estadística. Esta es una aproximación simple para incorporar explícitamente los datos geoestructurales en el análisis geotécnico de túneles excavados en macizos rocosos discontinuos, la cual optimiza el tiempo requerido para las etapas de diseño preliminar, pudiendo obtener resultados que se asimilan de mejor forma a la realidad. Cabe señalar que esta simplificación no afecta los resultados obtenidos.
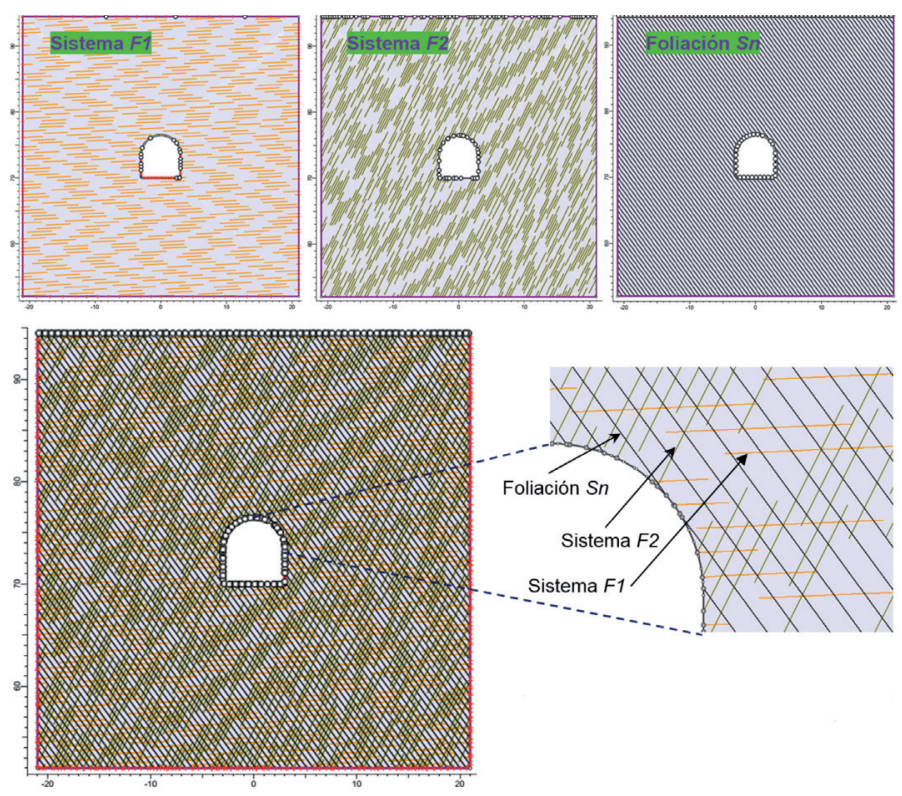

Figura 9: Geometría bi-dimensional de las mallas generadas para cada sistema de discontinuidades usando el método paralelo determinístico

\section{Análisis de resultados}

A continuación, son presentados los resultados de los análisis numéricos utilizando modelos semi-discontinuos del tramo de túnel indicado en la Figura 1c. Es importante indicar que este análisis de sensibilidad tiene el objetivo de definir preliminarmente, no definitivo, el estado de la estabilidad del túnel, debido a que aún se están generando datos geotécnicos importantes para el análisis final. Sin embargo, actualmente es posible verificar los patrones de falla definidos por la intersección de dos o más sistemas de discontinuidades, y la influencia de los datos geoestructurales en el modelo numérico. La Figura 10 muestra la variación de la distribución del estado de esfuerzo principal mayor, extensión de la zona de fluencia y la Figura 11 muestra la distribución de desplazamientos totales en el perímetro del túnel para tres escenarios distintos, los cuales simulan la degradación/disminución de propiedades. En este trabajo, el foco de análisis considera la fluencia de los sistemas de discontinuidades, los que inducen la formación e inestabilidad de bloques/ cuñas de roca en el contorno de la excavación.

(a)
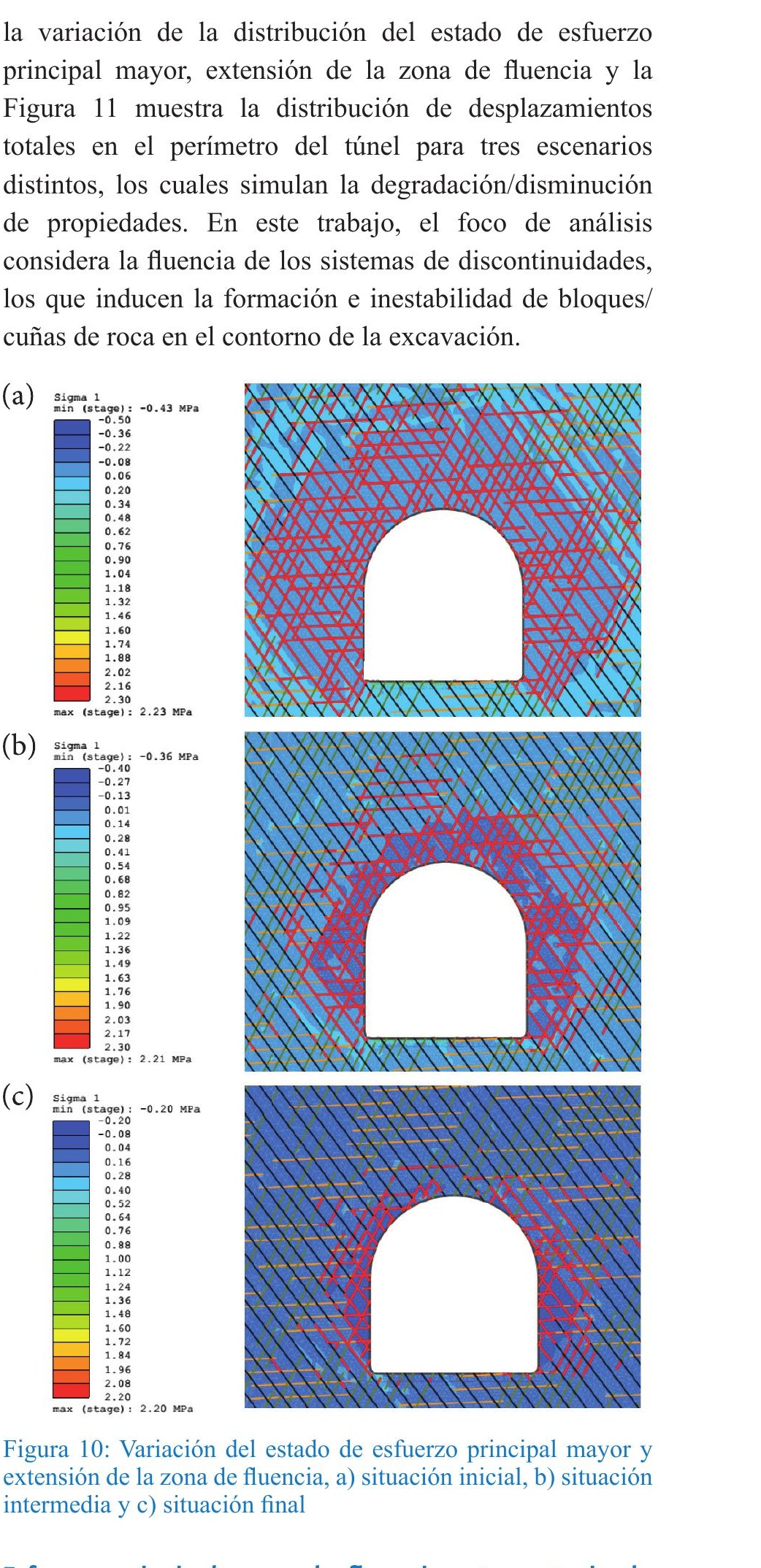

(b)

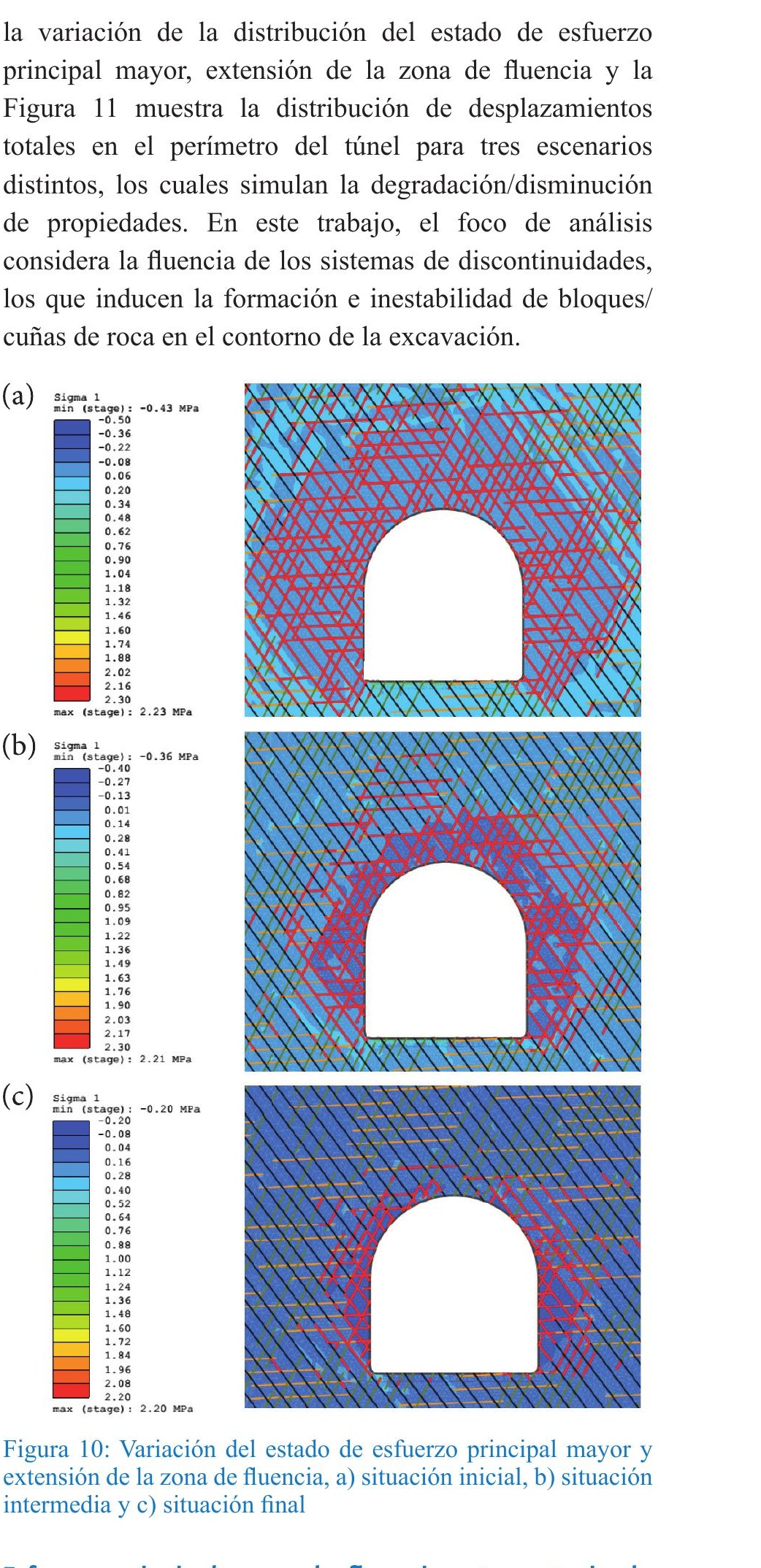

(c)
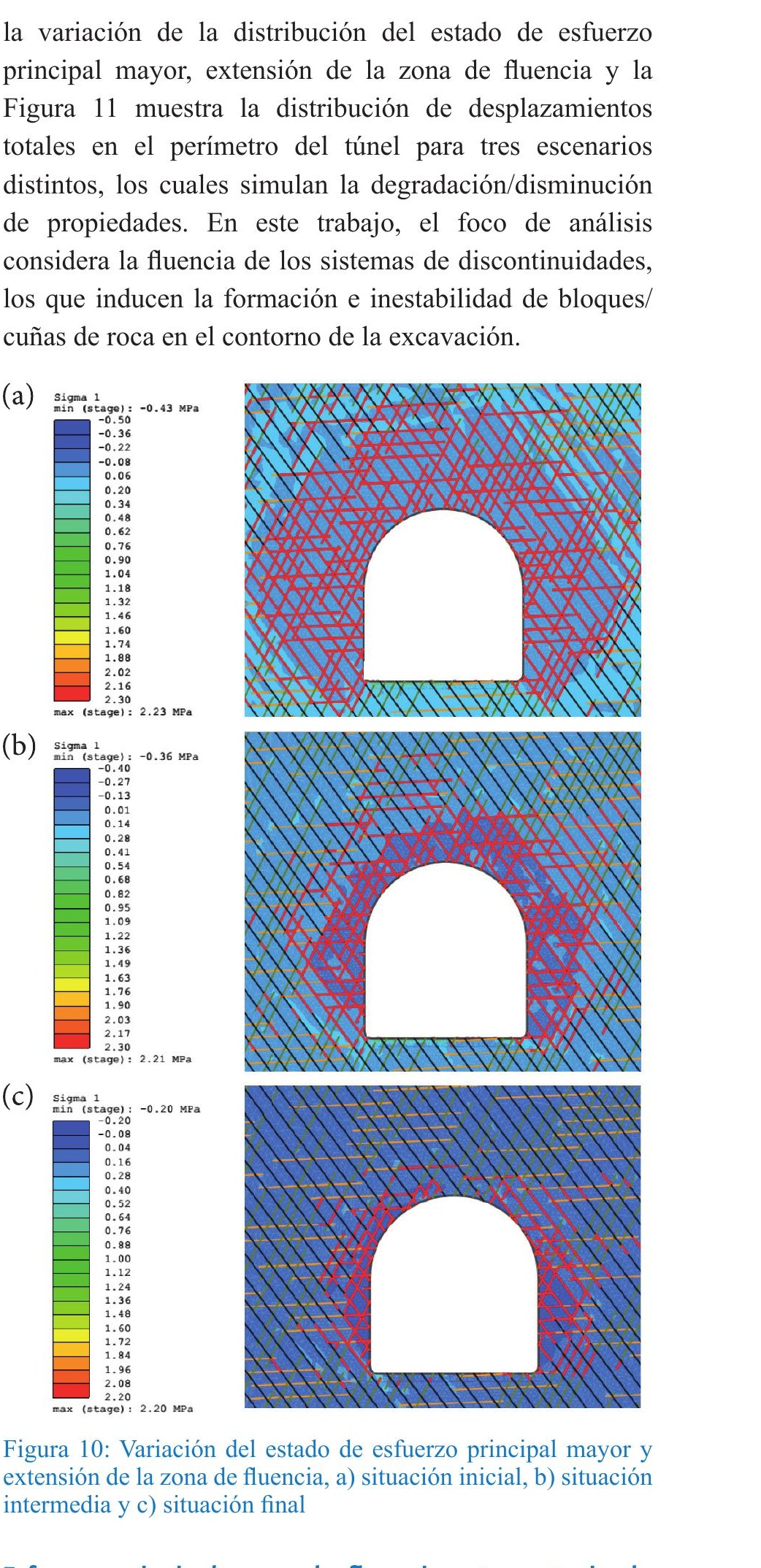

Figura 10: Variación del estado de esfuerzo principal mayor y extensión de la zona de fluencia, a) situación inicial, b) situación intermedia y c) situación final

Esfuerzo principal, zona de fluencia y trayectoria de desplazamientos

La zona perturbada alrededor del perímetro del túnel es la región donde el estado original de esfuerzos in situ del 
(a)

(b)
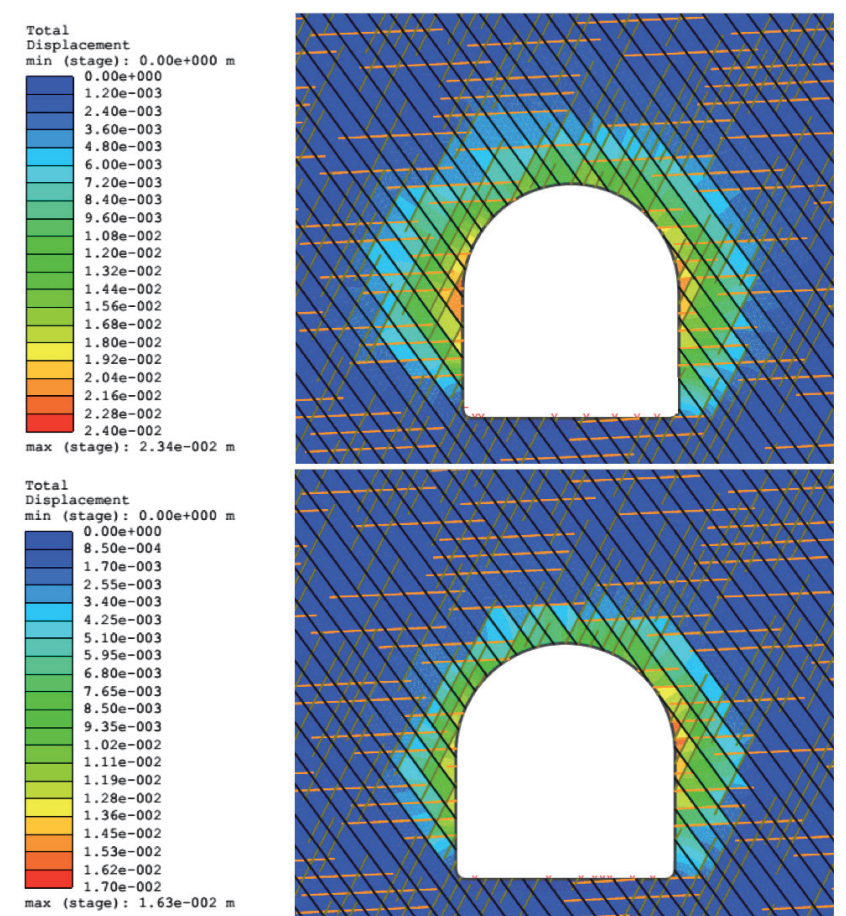

(c)
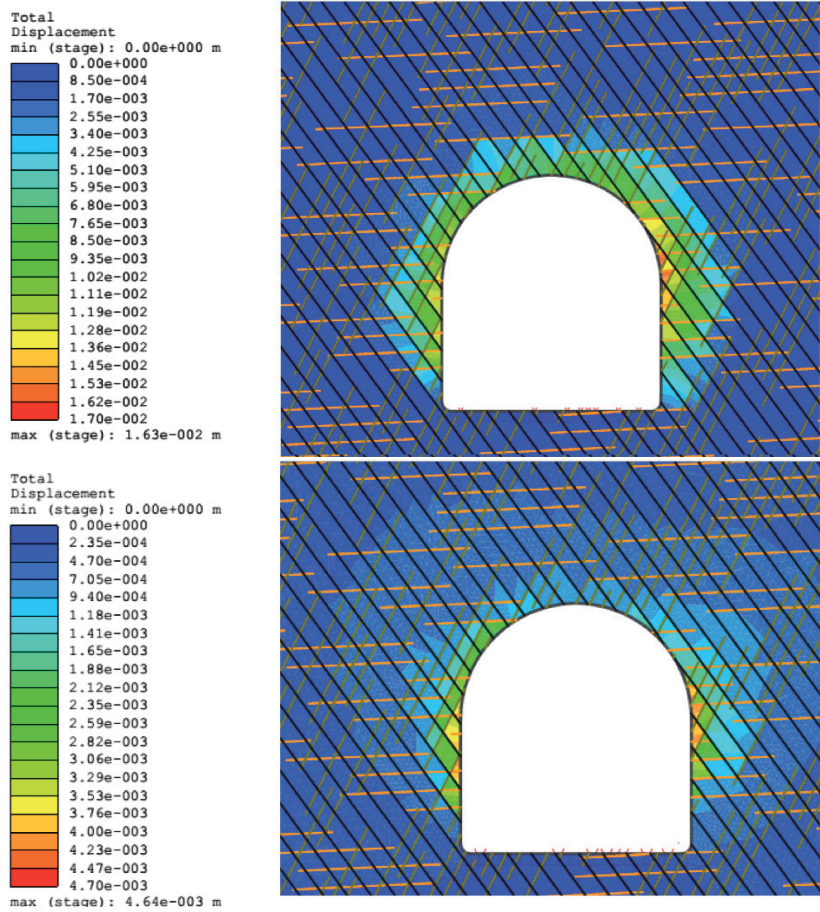

Figura 11: Variación de los desplazamientos totales y extensión de la zona de fluencia, a) situación inicial, b) situación intermedia y c) situación final

macizo rocoso ha sido afectado debido a la ejecución de la excavación. Esta es la zona donde normalmente los bloques/cuñas de roca tienen desplazamientos importantes y los esfuerzos tangenciales muestran un mayor aumento. De esta forma, los desplazamientos y esfuerzos son los factores que controlan la estabilidad del túnel.

Con el objetivo de simular la degradación de parámetros geotécnicos en el tiempo, las Figuras 10 y 11 muestran los resultados de tres situaciones (ver Tabla 3) que van desde el escenario más desfavorable (situación inicial), donde los parámetros mecánicos que definen la resistencia de los sistemas de discontinuidades han considerado los valores mínimos obtenidos en ensayos de laboratorio, hasta las situaciones intermedia y final.
La Figura 10a muestra una zona de fluencia con extensión media igual a $4.72 \mathrm{~m}$, que es un valor cercano al diámetro medio del túnel. Para este escenario los valores del esfuerzo principal mayor son muy bajos (entre 0.1 y 0.05 $\mathrm{MPa}$, llegando hasta valores negativos). Además, la Figura 11a muestra valores de desplazamientos totales altos, lo cual representa que todo el contorno del túnel se está desplazando entre 18 a $24 \mathrm{~cm}$. Con lo anterior, se tiene que la totalidad de los bloques y cuñas formados en las paredes y techo del túnel son inestables. Es importante señalar que esta situación no ha sido observada en terreno.

Por otro lado, la extensión media de la zona de fluencia para la situación intermedia fue igual a $2.2 \mathrm{~m}$ (Figura 10b). Similar a lo comentado para la situación inicial, los resultados obtenidos para esta situación representan un escenario poco probable, con valores muy bajos de esfuerzo principal mayor (cercanos a $0.15 \mathrm{MPa}$ ) y desplazamientos totales muy altos aún (5 a $17 \mathrm{~cm}$, ver Figura 11b), en una extensión mayor a $2 \mathrm{~m}$ en todo el contorno de la excavación, lo cual tampoco ha sido observado en terreno.

Los resultados de la situación final, con una extensión de la zona de fluencia menor a $1.5 \mathrm{~m}$, muestran una buena similitud con lo observado en terreno (Figuras 10c y 11c). Para este escenario se observan deslizamientos de bloques con ápices máximos cercanos a $1.5 \mathrm{~m}$ en la pared Este (pared derecha de las Figuras 11c, y 12a,b), lo cual se asemeja de muy buena forma con las mediciones realizadas dentro del túnel. Estos resultados son similares a lo observado en la Figura 12, donde se muestran cuatro perfiles de sobre-excavación del túnel Monte Seco, los cuales fueron medidos con TLS. Las mediciones de sobre-excavación realizadas demuestran que el tipo de falla comúnmente ocurrida dentro del túnel ha sido el deslizamiento de bloques con ápices inferiores a $1.5 \mathrm{~m}$ en la pared Este. También han sido observadas fallas localizadas en la pared Oeste con ápices entre 0.9 y 1.25 m.

\section{Conclusiones}

En el presente estudio se analiza el efecto de la inclusión de los datos geo-estructurales sobre la estabilidad de un tramo del túnel Monte Seco, utilizando información geológica y geotécnica. Para ello se emplean modelos numéricos del software FEM RS2 (2015), considerando un medio elastoplástico semi-discontinuo. Los resultados de la modelación 


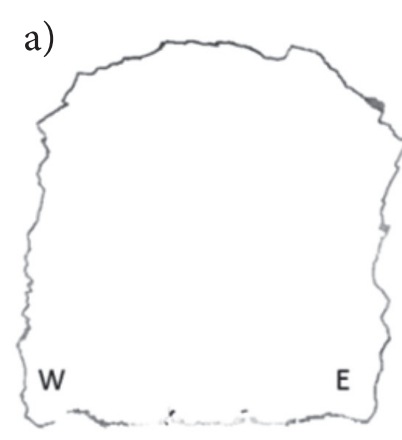

b)

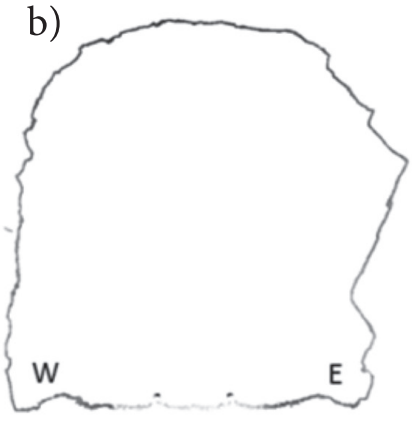

c)

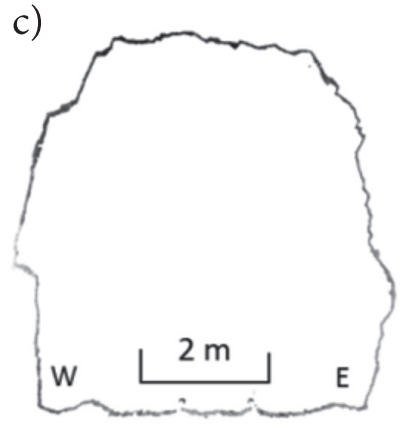

d)

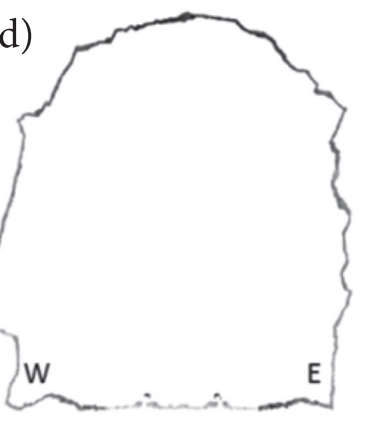

Figura 12: Perfiles de sobre-excavación medidos con TLS para el tramo de túnel estudiado (Cacciari, 2014)

numérica muestran una buena similitud con las mediciones de perfiles de sobre-excavación del túnel efectuadas con TLS. Con esto se logra verificar preliminarmente que la zona de fluencia del túnel tiene una extensión cercana a 1.5 $\mathrm{m}$, demostrando que el tipo de falla comúnmente ocurrida es el deslizamiento de bloques con ápices inferiores a 1.5 $\mathrm{m}$ en la pared Este y fallas localizadas en la pared Oeste con ápices entre 0.9 y $1.25 \mathrm{~m}$. Finalmente, se tiene que mientras aumente la degradación (disminución) de los parámetros mecánicos que definen la resistencia de los sistemas de discontinuidades, mayor va a ser la zona de fluencia en el perímetro de la excavación. Aun cuando este problema (parámetros mecánicos de los sistemas de discontinuidades) continúa siendo estudiado para el túnel Monte Seco, con los resultados del modelo numérico semidiscontinuo se pueden corroborar preliminarmente los patrones de falla observados en terreno.

\section{Agradecimientos}

Los autores agradecen a la Compañía VALE S.A. por al apoyo logístico y financiero del proyecto. El primer autor agradece a CONICYT Chile (Corporación Nacional de Investigación, Ciencia y Tecnología) por la beca otorgada para estudios de postgrado en el extranjero. Los co-autores agradecen a CNPq (Consejo Nacional de Desarrollo Tecnológico y Científico) por el apoyo financiero otorgado.

\section{Referencias}

Baecher, G.B., Lanney, N.A. and Einstein, H.H. (1977). Statistical description of rock properties sampling. 18th US Symposium on Rock Mechanics

Bandis, S., Lumsden, A.C. and Barton, N.R. (1981). Experimental studies of scale effects on the shear behaviour of rock joints. International Journal of Rock Mechanics and Mining Sciences \& Geomechanics Abstracts 18(1), 1-21

Barrios, B. (2014). Caracterização da rugosidade. Relatório de Iniciação Cientifica, Escola Politécnica da Universidade de São Paulo Barton, N., Bandis, S. and Bakhter, K. (1985). Strength, deformation and conductivity of rock joints. International Journal of Rock Mechanics and Mining Sciences \& Geomechanics Abstracts 22(3), 121-140

Barton, N. and Choubey, V. (1977). The shear strength of rock joints in theory and practice. Rock Mechanics \& Rock Engineering 10(1), 1-54

Bieniawski, Z.T. and Bernede, M.J. (1979). Suggested methods for determining the uniaxial compressive strength and deformability of rock materials. International Journal of Rock Mechanics and Mining Sciences \& Geomechanical Abstracts 16(2), 138-140

Cacciari, P. (2014). Estudo de um túnel em maciço rochoso fraturado por investigação geológico-geotécnica e analise pelo método dos elementos distintos. Tesis MSc, Escola Politécnica da Universidade de São Paulo

Cacciari, P. and Futai, M. (2015). Modelling a railway rock tunnel using terrestrial laser scanning and the distinct element method. South American Rock Mechanics Symposium, ISRM Specialized Conference, Buenos Aires, Argentina, 101-108

Cacciari, P. and Futai, M. (2016a). Mapping and characterization of rock discontinuities in a tunnel using 3D terrestrial laser scanning. Bulletin of Engineering Geology and the Environment 75(1), 223-237

Cacciari, P. and Futai, M. (2016b). Integrating terrestrial laser scanning and discrete fracture network approaches for tunnel modelling in fractured rock masses. VII Brazilian Symposium on Rock Mechanics, ISRM Specialized Conference, Belo Horizonte, Brazil 
Call, R.D., Savely, J.P. and Nicholas, D.E. (1976). Estimation of joint set characteristics from surface mapping data. 17th US Symposium on Rock Mechanics, 2B2-1-9

Diederichs, M. (2007). Mechanistic interpretation and practical application of damage and spalling prediction criteria for deep tunnelling. Canadian Geotechnical Journal 44(9), 1082-1116

Elmo, D., Liu, Y. and Rogers, S. (2014). Principles of discrete fracture network modelling for geotechnical applications. First International DFNE Conference, Vancouver, Canada, paper 238

Hoek, E., Carranza-Torres, C. and Corkum, B. (2002). HoekBrown criterion - 2002 edition. 5th North American Rock Mechanics Symposium and the 17th Tunnelling Association of Canada Conference NARMS-TAC, Toronto, 1, 267-273

Hasui, Y., Carneiro, C.D.R., Almeida, F.D. and Bartorelli, A. (2012). Geologia do Brasil. São Paulo, Beca

Ito, W. (2016). Contribuição ao estudo de instabilidade em tuneis não revestidos da estrada de ferro Vitória-Minas através da teoria dos blocos-chave e caracterização da rocha através de ensaios de laboratório e campo. Tesis MSc, Escola Politécnica da Universidade de São Paulo

Kulatilake, P.H.S.W. and $\mathrm{Wu}$, T.H. (1984). Estimation of mean trace length of discontinuities. Rock Mechanics \& Rock Engineering 17(4), 215-232

McMahon, B. (1974). Design of rock slopes against sliding on preexisting surface. 3rd International Symposium on Rock Mechanics, 803-808
Monticelli, J. (2014). Contribuição ao conhecimento dos condicionantes geológicos - geotécnicos do túnel Monte Seco. Relatório de Iniciação Cientifica, Escola Politécnica da Universidade de São Paulo

Monticelli, J., Cacciari, P., Susuki, S. e Futai, M. (2014). Correlação entre índices físicos e analise petrográfica na determinação do grau de alteração de um gnaisse. VI Brazilian Symposium on Rock Mechanics, ISRM Specialized Conference, Goiania, Brazil

Priest, S.D. and Hudson, J.A. (1981). Estimation of discontinuity spacing and trace length using scanline surveys. International Journal of Rock Mechanics and Mining Sciences \& Geomechanical Abstracts 18(3), 183-197

RS2 (2015). Finite element analysis for excavations and slopes software. Version 8.0, Rocscience Inc., Toronto

Ulusay, R. (2015). The ISRM suggested methods for rock characterization, testing and monitoring: 2007-2014. International Society of Rock Mechanics ISRM. Springer

Villaescusa, E. and Brown, E.T. (1992). Maximum likelihood estimation of joint size from trace length measurements. Rock Mechanics \& Rock Engineering 25(2), 67-87

Zhang, L. and Einstein, H.H. (2000). Estimating the intensity of rock discontinuities. International Journal of Rock Mechanics \& Mining Sciences 37(5), 819-837 